\title{
Cognitive Perspective of Lexical Metaphor in Scientific Language
}

\author{
Zhang Na \\ School of Foreign Languages and Cultures, Beijing wuzi University, Beijing, China \\ zhangna@bwu.edu.cn
}

\begin{abstract}
Contemporary metaphor research offers a cognitive view to help understand the existence of metaphor used in scientific language. Different from literary metaphor, used as a decorative device, lexical metaphor in scientific language has its unique features. And it serves not decorative function any more, but naming function, exegetical or pedagogical function and theory-constitutive function. With the understanding of reasons of lexical metaphor used in scientific language, people can have a deeper understanding of language and its metaphorical uses. function

Index Terms - lexical metaphor, cognition, scientific language,
\end{abstract}

\section{Introduction}

The study on metaphors has been going on for thousands of years since Aristotle. The fundamental aspect in a metaphor is variation and transference of a word meaning. The metaphor at this level is called lexical metaphor. For the reason that metaphor is traditionally taken as a decorative device, lexical metaphors are avoided in scientific language. However, this is a reality that lexical metaphors exist even in abundance in scientific language, such as virus in computer science and appendix in medicine science. How could metaphors occur in scientific language and what's special about them? New perspectives of metaphor can offer appropriate explanations for the existence of lexical metaphors in scientific language.

\section{Contemporary Metaphor Research}

The rising and development of modern linguistics set the basis for contemporary metaphor theories. Different views of these theories differ mainly in their regard or disregard for the cognitive function of metaphor and the two kinds of views are entitled by Ortony (1993) and Kittay (1987) with the terms "constructivism" and "nonconstructivism".

The representative of "nonconstructivism" is TG school whose fundamental idea is that metaphor involves nothing but some deviant linguistic forms. In addition, the influence of the traditional view of metaphor never ceases during the 20th century. These views constitute the main content of nonconstructivism.

Constructivism is promoted by the interactionists with Black as the chief. On the basis of Richards' interaction between "tenor" and "vehicle", Black (1993) points out that the nonstandard effect has to be constructed by resorting to the linguistic context in which the metaphor appears, instead of being directly inferable from the standard lexicon. Therefore, there is difference at most in degrees instead of in essence between the metaphorical expression and literal expression. To get more serious and insightful investigations, the perspective of cognitive approach is the greatest help.

Lakoff and Johnson (1980) initiate their arguments with a harsh criticism of the traditional view of metaphor as "a device of poetic imagination" and "the rhetorical flourish". They offer their cognitive view of metaphor: "The essence of metaphor is understanding and experiencing one kind of thing in terms of another". In other words, metaphor has come to mean "a cross domain mapping in the conceptual system" and should be understood as "metaphorical concepts" (Lakoff, 1993). The locus of it is not in language at all, but "in the way we conceptualize one mental domain in terms of another" (Lakoff, 1993).

In Lakoff's The Contemporary Theory of Metaphor, he makes one statement that "metaphor is fundamentally conceptual, not linguistic, in nature" (Lakoff, 1993). And "the essence of metaphor is understanding and experiencing one kind of thing in terms of another"(Lakoff \& Johnson, 1980), therefore, metaphor should be understood as "metaphorical concepts". According to Lakoff and Johnson, metaphors can be classified into structural, orientational and ontological metaphor. Structural metaphors refer to the cognitive process by which the language speakers "use one highly structured and clearly delineated concept to structure another". Orientational metaphors organize "a whole system of concept" with respect to spatial orientation, while ontological metaphors represent the process in which "our experience of physical objects and substances provides a further basis for understanding".

Kittay (1987) emphasizes the cognitive power of metaphor and metaphor as being irreducible. And Hintikka (1994) looks into the cognitive function and functioning of similarity-creating metaphors.

\section{Metaphor and Science}

Science is generally regarded as the epitome of rational theorizing, careful observation, and efficient application (Hoffman, 1985: 327). Black (Boyd, 1993) claims that metaphorical language lacks scientific precision. And in Ortony's (1993) introduction to the book Metaphor and Thought, he states that "science is supposed to be characterized by precision and the absence of ambiguity and the language of science is assumed to be correspondingly precise and unambiguous-- in short literal." Therefore, the theories of taking metaphor as a kind of rhetorical device to achieve stylistic effect can not be applied in analyzing scientific language and is historically avoided in scientific 
discourse. And "we need the metaphors in just those cases where there can be no question as yet of the precision of scientific statements" (Boyd, 1993: 482).

However, the attitude towards metaphor in scientific language has changed with the appearance of the contemporary theories of metaphor. Today, metaphor is no longer deemed illicit and a violation of the scientific discourse principles of clarity, precision and verifiability. Rather, it is recognized as one of the deepest and most persisting phenomenon of thinking and theory building. Metaphor and science are not in conflict. Conversely, metaphor is a way of thinking or reshaping human experience. Metaphors are deliberately used by scientists, who are usually aware (sometimes painfully) that their hypotheses are metaphorical and speculative. Advocacy of the existence of literal scientific statements does not eliminate the need for metaphors. Boyd (1993) also argues that there is an important class of metaphors which plays a role in the development and articulation of theories in relatively mature sciences. Conversely, that a scientific metaphor helps in the generation of theories does not mean that all the statements derived from the theory must be metaphorical (Hoffman, 1985: 329).

\section{The Features of Lexical Metaphor in Scientific Language}

The use of metaphor is related with the genre of language, therefore, to explore the features of metaphor in scientific language, we need to explore the lexical features of EST first and then the features of lexical metaphor in scientific language.

\section{A. The lexical features of scientific language}

The vocabulary of scientific language consists of three categories generally: common words, semi-technical words and technical words. Technical words are those with precise, narrow meanings, such as superconductivity, bionics, hemophilia, etc. It is proved that the frequency of this kind of words is the lowest among the three categories. Semi-technical words can be seen in both scientific language and ordinary English, such as power, charge, force, carrier, solution, etc. The meanings of these words in EST are likely to differ from their ordinary meanings. Moreover, they may have different precise meanings in different technical fields. This category of words covers an essential part of the words in the vocabulary of scientific language. And some data analysis proves that the percentage of semi-technical words is more than $81 \%$ in general writings of scientific language.

From the composition of the vocabulary in scientific language, we can see that semi-technical words take the major part in vocabulary of scientific language and share the same source with the vocabulary in ordinary English. According to cognitive science, this kind of phenomenon in which the same word has several meanings is the process of meaning extension from the central or basic meaning of a word to other meanings through metaphor or metonymy in human cognitive process. It is the product of the categorization and conceptualization of human cognition.

\section{B. The features of lexical metaphor in scientific language}

Scientific language is always supposed to be literal, logical, precise, and directly verifiable. Therefore, figurative devices which are decorative are inappropriate for the style of scientific language. This feature of scientific language is different from that of ordinary English, especially from that of literary language such as poetry.

Metaphor, however, taken as a tool of thinking or reshaping human experience in contemporary theories, occurs in abundance in scientific language. The function of it is not decorative any longer but cognitive in scientific language.

To show the features of lexical metaphor in scientific language clearly, we take literary metaphor as reference. The common point of the two kinds of metaphors lies in that they can be accepted by language system, if they are successful, and then become new language resource. However, lexical metaphor, as a main aspect in the linguistic features of a variety, has different characteristics in different varieties of language.

\section{1) The frequency of occurrence}

Although lexical metaphors are often used in literary works, they are only a small part of figurative language for there are other figurative uses of language in literary works such as simile, metonymy, hyperbole, personalization, etc. In scientific language, there are barely other kinds of figurative language except metaphor. Therefore, metaphorical language takes the major part even the whole of figurative language in scientific language.

\section{2) The reasons of occurrence}

The occurrence of metaphor is a complex process which resulted from the interaction of several reasons. Metaphor may be used out of the limitation of human cognition; it may be used to remedy gaps in vocabulary; and it may be used to create special effects.

In literature, although metaphor is sometimes used for the first two reasons, it is more often used to create special effects, such as, to make the expression more vivid, more attractive or even more unusual. In scientific language, however, metaphor is mainly used to help us recognize or name things, and to convey more information logically. There is no need or necessity to arouse audiences' or readers' curiosity by metaphors in scientific language, because scientific language conveys the facts or the truth, not the feelings or personal opinions.

In a word, metaphors are used in literature mostly deliberately by writers or speakers for their personal purposes, while in EST they are used mostly inevitably for cognitive or linguistic reasons.

\section{3) The mapping process}

In contrast, the essential difference between scientific metaphor and literary metaphor lies in mapping process of metaphor. 
First, the mapping process of scientific metaphor is oneto-one mapping, while in literary metaphor it is many-to-one mapping. For example, the metaphor "an atom is a miniature solar system" in scientific language is a good one to explain the inner structure of an atom. Through the mapping from the solar system to an atom, the atom is best described and recognized. And metaphors like this one in scientific language become, when they are successful, the property of the entire scientific community. In literature, however, mapping process is often from more source domains to the target domain. Take "life" for instance. In literature, "life" can be used metaphorically as "stage", or "road", or "journey". Therefore, the mapping process can be from stage to life or from road to life or from journey to life, depending on different users from different opinions.

Second, the mapping process of scientific metaphor is basically from the known, familiar or concrete to the unknown, unfamiliar or abstract. The necessity of recognizing new things in EST makes the mapping process proceed from the simple to the complex. In literary metaphor, the case is sometimes the opposite. There are cases that the mapping process is from the complex to the simple to make special effects. Take one sentence in Stephen Spender's well-known poem Seascape (Indurkhya, 1992: 42) for an example.

"Afternoon gilds all the silent wires into a burning music for the eyes." In this sentence, the concrete thing "the silent wires" (of a harp which is the metaphorical form of an ocean) is gilded by the sunlight of afternoon into an abstract thing "a burning music" for the eyes.

Third, the mapping process of scientific metaphor can be described or understood clearly and definitely. In literary metaphor, it is often ambiguous with more than one kind of explanations or understandings. That is, the meaning of scientific metaphor is clear, definite and single while literary metaphor may have several kinds of explanations or understandings. There are many cases that in literature one thing has several metaphorical meanings such as "road" in Robert Frost's poem The Road Not Taken.

\section{$V$. The functions of lexical metaphor in scientific language}

Since metaphor as a kind a figure of speech is excluded out from scientific language, naturally its function of being a kind of decorative device does not exist in scientific language. It is the cognitive function of metaphor that makes it inevitable and necessary in scientific language. In its various manifestations, lexical metaphor serves several kinds of useful functions.

\section{A. Naming function}

On the basis of different kinds of similarities, the unknown scientific concepts or technical things borrow their names from the known or familiar ones. In this process, metaphor plays a very important role by giving a new thing a familiar name. It is the transference of meaning from a familiar thing to a strange scientific thing that makes people to understand and accept the new thing readily. Thus, by converting common words into technical terms, metaphor is endowed with the function of naming new scientific concepts or technical things.

In comparison with similarity-based metaphor, similaritycreative metaphor plays more important role in creative problem solving or building scientific theories. An example is that about Kekule (Indurkhya, 1992:62) who comes up with the idea that carbon atoms in the benzene molecule may be arranged in the form of a ring when he dreams of a serpent swallowing its own tail. Here there is an image that leads to the solution of a problem. After the solution, one could see the similarities between the molecular structure of benzene and a snake swallowing its tail. But before that, there are no similarities. The image of the snake suggests an idea that turns out to be fruitful.

The cognition process of human being towards the world is generally from the concrete to the abstract, from the familiar to the unfamiliar, and from the known to the unknown. With the rapid development of the society and modernization process, a great quantity of new things are found or created. How to name so large a group of new things is a big problem not merely for scientists or technologists. Science and technology need to be concerned by each one in the society. In addition, the limitation of human's memory and language system makes it impossible to give each new thing a new name. Therefore, metaphor is inevitably used in scientific language as a means of naming news things on the basis of similarities.

In comparison with similarity-based metaphor, similaritycreative metaphor plays more important role in creative problem solving or building scientific theories. One typical example is the naming process of elementary particle in Quantum Mechanics. When American theoretical physicist Murray Gellmann points out that elementary particle can be divided into smaller components, he names this kind of component "quark". The word "quark" is originally created as onomatopoeia by the novelist James Joyce. Gellmann borrows this interesting word to name the elementary particle which he has found. Then the first three kinds of "quark" is called by him "up", "down" and "sideways", and the next three kinds he has found later is named "charm", "truth" and "beauty". The most interesting thing is that different kinds of "quark" has different "flavor" and the quark with the same "flavor' is divided into three kinds of "color": "red", "green" and "blue". Of course, "flavor" and "color" used here have no relationship with those of our daily life. Thus, the naming process by Gellmann is seen to be the results of metaphorical thinking. Through the metaphorical process of naming the elementary particle, these particles are endowed with impression which is familiar for us. Thus they are recognized more easily. As a result, the findings of these components improve the study in the field of quantum mechanics.

\section{B. Exegetical or pedagogical function}

The use of metaphor is one device available to the scientific community to accomplish the task of introducing 
scientific terminology, and modifying usage of existing terminology. This kind of metaphor, which is termed according to Boyd (1993) as exegetical or pedagogical metaphor, plays a role in the teaching or explication of theories which may already admit of entirely adequate nonmetaphorical (or, at any rate, less metaphorical) formulations. In other words, even some scientific concepts or theories can be explicated by literal language, metaphor makes them easier to be taught or expounded.

A typical example is the analogy between the solar system and atom. With the prior knowledge about the solar system in which the sun is enclosed by many planets, one can easily understand the atom as a miniature solar system because the center of the atom is the nucleus which is enclosed by many electrons. In addition, those electrons move around the nucleus in certain orbits just like those planets moving around the sun. Therefore, the metaphor "atom is a miniature solar system" plays an important role in finding and explicating the inner structure and moving law of atom.

Another example is about a kind of black poisonous spider in South America. For this kind of spider, there is a scientific name in biology called "latrodectus mactus". However, it is now renamed "black widow" which is easily remembered and understood. The new name is a metaphorical one on the basis of similarity that this kind of spider often kills its mate spider after their mating, and makes itself to be a "widow". It is seen that the new metaphorical name describes the spider's characteristic and can give people a deep impression of it.

By using this kind of exegetical or pedagogical metaphor, scientific concepts can be easily accepted and understood even by a layman.

\section{Theory-constitutive function}

There exists an important class of metaphors which are constitutive, rather than merely exegetical in scientific theories or terminology. This kind of metaphor can be called theoryconstitutive metaphor. It plays a role in the development and articulation of theories in relatively mature sciences.

There are cases that scientists use this kind of metaphor to express theoretical statements for the reason that no adequate literal paraphrase can be used. If one looks at the theory construction in the relatively young sciences such as computer science, one finds theory-constitutive metaphors in abundance. The following examples are but a few actual cases:

1) the claim that computer is a sort of "electric brain".

2) the suggestion that computer owns computer language or machine language.

3) the fact that certain information is "stored" or "remembered" by computer.

4) the case that computer system can be "destroyed" or "infected" by computer virus.
From these examples we can see that computer science shows much concern with exploring similarities between computer and human being. These metaphors have provided much of the basic theoretical vocabulary of contemporary computer science. Thus, these computer metaphors play theory-constitutive function in the science of computer.

\section{Conclusion}

In the scientific language, there are many technical words which get their meanings from the variation of their original meanings in daily discourse. The variation of meaning almost experiences a process of metaphorization, that is, the process of metaphorical transference of a meaning from the source domain to the target domain. Compared with metaphor in literary language, lexical metaphor in scientific language has its unique features and functions. Based on the analysis above, it is not difficult to summarize the reasons for the metaphorical use of words in scientific language. They can be roughly divided into two kinds: cognitive reasons and language reasons. On the one hand, metaphor as a way of thinking is an important vehicle in scientific thought. On the other hand, the abundance of new things with the rapid development of society need to be expressed in language, however, the existing language system could not afford enough words for them, or the existing academic word is too hard even for academic people to remember and understand. The two kinds of reasons often interact with each other. Therefore, the appearance of lexical metaphor is often the result of the interaction of the two reasons. No matter what reason it is, lexical metaphor is an inevitable phenomenon in scientific language. With the understanding of the features and functions of lexical metaphor in scientific language, one can understand scientific language more easily and have a deeper understanding of its metaphorical uses.

\section{References}

[1] Black, M. "More about metaphor". IN Ortony (ed.), Metaphor and Thought (Second Edition ). Cambridge: Cambridge University Press. pp19-41. 1993.

[2] Boyd. R, 'Metaphor and theory change: What is 'metaphor' a metaphor for?" In Ortony (ed.), Metaphor and Thought (Second Edition). Cambridge: Cambridge University. pp.481-532, 1993.

[3] Hintikka, J. (ed.). Aspects of metaphor. Boston/London: Kluwer Academic Publishers. 1994.

[4] Hoffman, R. "Some implications of metaphor for Philosophy and psychology of science". IN Paprotté, W. \& Dirven (ed.), The Ubiquity of Metaphor. Amsterdam/Philadelphia: John Benjamins Publishing Company. 1985.

[5] Indurkhya. B, Metaphor and Cognition: An interactionist approach, Dordrecht/Boston/London: Kluwer Academic Press, 1992.

[6] Kittay, E. F. Metaphor: Its cognitive force and linguistic structure. Oxford: Oxford University Press. 1987.

[7] Lakoff. G, "The contemporary theory of metaphor". In Ortony (ed.), Metaphor and Thought (Second Edition). Cambridge: Cambridge University. pp202-249, 1993

[8] Lakoff. G. \& M. Johnson, Metaphors We Live By, The University of Chicago Press, Chicago, 1980.

[9] Ortony, A. (ed.). Metaphor and Thought (Second Edition). Cambridge: CambridgeUniversity.1993. 